\title{
BDNF regains function in hippocampal long-term potentiation deficits caused by diencephalic damage
}

\author{
Lindsey C. Vedder and Lisa M. Savage \\ Department of Psychology, Behavioral Neuroscience Program, Binghamton University, State University of New York, Binghamton, \\ New York 13902, USA
}

\begin{abstract}
Thiamine deficiency (TD), commonly associated with chronic alcoholism, leads to diencephalic damage, hippocampal dysfunction, and spatial learning and memory deficits. We show a decrease in the magnitude of long-term potentiation (LTP) and paired-pulse facilitation (PPF) at CA3-CAl synapses, independent of sex, following diencephalic damage induced by TD in rats. Thus, despite a lack of extensive hippocampal cell loss, diencephalic brain damage down-regulates plastic processes within the hippocampus, likely contributing to impaired hippocampal-dependent behaviors. However, both measures of hippocampal plasticity (LTP, PPF) were restored with brain-derived neurotrophic factor (BDNF), revealing an avenue for neural and behavioral recovery following diencephalic damage.
\end{abstract}

Learning and memory requires the interaction of many brain areas in a dynamic circuit, with each brain area contributing critical information toward an effective behavioral response (Scoville and Milner 1957; Tulving 1987). The direct and indirect connections between brain areas required for successful learning and memory can set the stage for abnormal function of one region within the circuit to lead to dysfunction in other areas within the circuit. For example, damage to the nuclei of the diencephalon (anterior thalamus and mammillary bodies) can lead to spatial learning and memory deficits similar to what is seen with direct hippocampal damage (Aggleton et al. 1995). Evidence supports that lesions of the diencephalon cause abnormalities in other brain areas critical to learning and memory, including the hippocampus and retrosplenial cortex (Savage et al. 2003; Dumont et al. 2012; Aggleton and Nelson 2015).

Thiamine deficiency (TD) leads to persistent neural loss within the diencephalon that is associated with amnesia. WernickeKorsakoff syndrome (WKS), a type of diencephalic amnesia associated with chronic alcohol abuse, is attributed to severe TD (Kopelman et al. 2009). There is also evidence that more moderate TD plays a role in alcohol-related cognitive and memory problems (Pitel et al. 2011). A rodent model of WKS, pyrithiamine-induced thiamine deficiency (PTD), recapitulates the diencephalic pathology observed in WKS patients, including damage to the mammillary bodies, anterior thalamic nuclei, and midline thalamic nuclei (Mair 1994; Langlais et al. 1996). The PTD model also exhibits deficits in spatial working memory that persists for months after recovery from TD (Pitkin and Savage 2004; Vedder et al. 2015).

Despite evidence that suggests that women may be more susceptible to TD and alcohol-related brain damage (Harper 1983; Mancinelli et al. 2013; Nixon et al. 2014), female rodents are often excluded in alcohol-related brain damage studies. In the current study, we investigated the effects of TD in both male and female rats on functional measures of hippocampal plasticity that included spontaneous alternation and long-term potentiation (LTP). Male and female rats were randomly sorted into two treatment groups, PTD (male, $N=7$; female, $N=8$ ) and pair-fed control (PF, male, $N=10$, female, $N=10$ ). During treatment, all rats were fed a thiamine-deficient diet (Harlan Laboratories, Inc.)

\section{Corresponding author: Isavage@binghamton.edu}

Article is online at http://www.learnmem.org/cgi/doi/10.1101//m.043927. 116. and injected daily with either pyrithiamine hydrobromide (PTD, $0.25 \mathrm{mg} / \mathrm{kg}$, i.p, Sigma-Aldrich) or thiamine (PF, $40 \mathrm{mg} / \mathrm{kg}$, i.p., Sigma-Aldrich). For PTD-rats, standard PTD treatment parameters were followed that produce significant thalamic and mammillary body damage, but allow for success in animal survival (Zhang et al. 1995; Savage et al. 2012). Thiamine deficiency was arrested with a dose of thiamine $(100 \mathrm{mg} / \mathrm{kg}$, i.p) $4.25 \mathrm{~h}$ after the observance of a seizure (11-14 d of treatment; see Fig. 1 for experimental design), and a second dose of thiamine was given $12 \mathrm{~h}$ later. As PTD-treated rats lose weight due to malaise toward the end of treatment, the standard control condition of PF rats were food-restricted to match PTD weight loss (86\% of initial pretreatment body weight). All rats were allowed to recover in their home cages for 3 mo until behavioral assessment of spatial memory, a simple spontaneous alternation assay on a four-arm plus maze. The day before testing, rats were fasted overnight to increase exploratory behavior on test day. During testing, rats were placed in the center of a plus maze $(72 \times 40 \times 36 \mathrm{~cm}$, with clear plastic sides on a wood base painted black) and the arm entry locations were recorded for $18 \mathrm{~min}$. An alternation was scored as an entry into four different arms on overlapping successive sequences of four arm entries (e.g., using the successive 15 arm entries of A, D, C, B, D, A, C, D, B, D, A, C, D, A, C, the first sequence of fourarm entries $\mathrm{ADCB}$ is counted as an alternation, but the following sequence of four arm entries DCBD would not). A single-arm entry was defined as all four paws of the rat within the arm. The percent alternation score is determined by the ratio of (actual alternations/possible alternations [trial number-3]) multiplied by 100 (for this data set: $5 /(15-3)=0.416 \times 100=41.6 \%)$. This criterion is based on previous experiments that have used a four-choice metric (Mohler et al. 2012; Ragozzino et al. 2012; Hall et al. 2014). Chance performance on this task when scoring out of a four-choice sequence is $9.3 \%([(4 / 4)(3 / 4)(2 / 4)(1 / 4)=0.093 \times$ 100] see Lennartz (2008)).

We found that TD, regardless of sex, led to significant spatial memory impairment (Fig. 2A, two-factor ANOVA, main effect of

(C) 2017 Vedder and Savage This article is distributed exclusively by Cold Spring Harbor Laboratory Press for the first 12 months after the full-issue publication date (see http://learnmem.cshlp.org/site/misc/terms.xhtml). After 12 months, it is available under a Creative Commons License (AttributionNonCommercial 4.0 International), as described at http://creativecommons. org/licenses/by-nc/4.0/. 


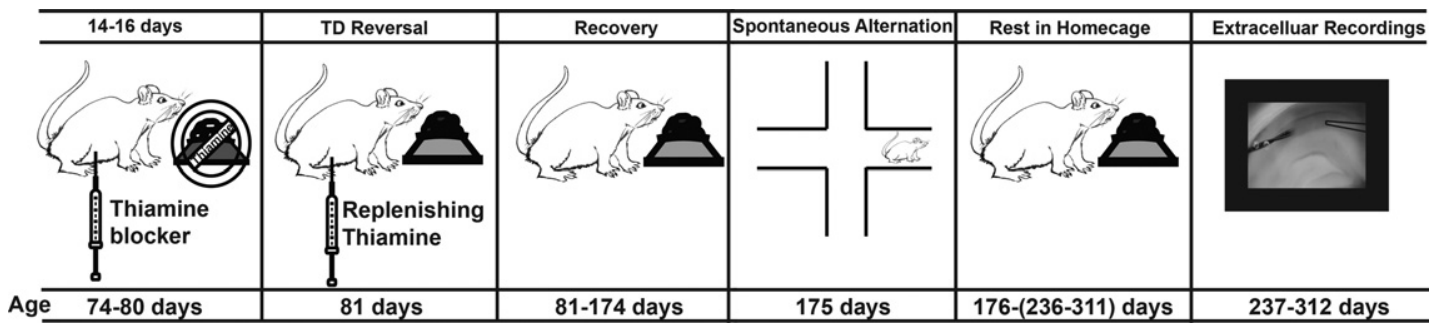

Figure 1. Schematic of the experimental treatments and timeline.

treatment (PTD versus PF), $\left.F_{(1,35)}=5.95, P<0.05\right)$, lack of sex effect, $F_{(1,35)}=0.26, P>0.61$, and lack of Sex $\times$ Treatment Interaction, $\left.F_{(1,35)}=0.12 P>0.72\right)$. For spontaneous alternation, female rats were all tested on the same day and the estrous cycle stage was not documented. To determine whether female hormonal fluctuations produced increased variance, we conducted an F-test (McCarthy et al. 2012), which revealed that the variance between male and female rats was not significantly different on this task (males: $\mathrm{s}=0.014$, females: $\mathrm{s}=0.018, F_{(15)}=0.79$, $P>0.32$ ).

Although several studies exist demonstrating that long-term chronic (months) ethanol exposure impairs hippocampal LTP, even after prolonged abstinence (Durand and Carlen 1984; Tremwel and Hunter 1994; Peris et al. 1997), very little is known about the specific effects of TD on hippocampal synaptic plasticity. We have shown that TD reduces the amount of acetylcholine in the hippocampus during spontaneous alternation and that these decreased levels of acetylcholine are correlated to alternation performance (Hall and Savage 2016). Furthermore, studies of anterior thalamic nuclear lesions have shown decreased levels of the immediate early gene c-Fos in the hippocampus (Dupire et al. 2013), a molecular measure of plasticity. LTP, a long-term increase in synaptic efficacy, is considered a cellular correlate to learning and memory (Malenka and Bear 2004). LTP at CA3 Schaffer collateral synapses onto CA1 pyramidal cells is often associated with spatial learning and memory processes. As TD disrupts spatial working memory, we hypothesized it would also disrupt normal synaptic function, but it was unknown whether sex would alter hippocampal responsivity to TD. Both male and female PF and PTD rats were injected with a lethal dose of sodium phenobarbital and transcardially perfused with ice-cold highsucrose aCSF (containing in $\mathrm{mM} ; 85$ $\mathrm{NaCl}, 2.5 \mathrm{KCl}, 4 \mathrm{MgSO}_{4}, 0.5 \mathrm{CaCl}_{2}, 1.25$ $\mathrm{NaH}_{2} \mathrm{PO}_{4}, 25 \mathrm{NaHCO}_{3}, 25$ glucose, and 75 sucrose, bubbled with $\mathrm{CO}_{2} / \mathrm{O}_{2}[95 \% /$ 5\%]). Acute, coronal hippocampal slices were cut at $400 \mu \mathrm{m}$ on a vibratome (Leica) in the high-sucrose aCSF solution. Hippocampal slices were stored in normal aCSF (in $\mathrm{mM} ; 119 \mathrm{NaCl}$, $26 \mathrm{NaHCO}_{3}, 2.5 \mathrm{KCl}, 1 \mathrm{NaH}_{2} \mathrm{PO}_{4}, 2.5$ $\mathrm{CaCl}_{2}, 1.3 \mathrm{MgSO}_{4}$, and 10 glucose) for at least $1 \mathrm{~h}$ at room temperature before recordings. Physiological recordings were performed on a four-chamber SliceMaster system (Scientifica). During recordings, slices were submerged in normal aCSF warmed to $32^{\circ} \mathrm{C}$ and a bipolar stimulating electrode constructed of two twisted nichrome wires generated extracellular dendritic field potentials (fEPSPs). For LTP experiments, events were stimulated using an established LTP induction protocol (Kauer et al. 1988; Smith and McMahon 2005, 2006); briefly, $0.1 \mathrm{~Hz}$ stimulation and a voltage that elicited a fEPSP with an amplitude of $0.5 \mathrm{mV}$ ( $\sim 50 \%$ of maximal response). After $10 \mathrm{~min}$ of stable baseline recordings ( $<4 \%$ variance in baseline slope), a high-frequency tetanus was given $(100 \mathrm{~Hz}, 0.5 \mathrm{sec}, 4 \times, 1.5$ times the baseline voltage, to allow for reliable, moderate LTP) and then returned to the baseline stimulus. This LTP protocol has been previously used to assess the influence of female sex hormones on hippocampal plasticity (Smith and McMahon 2005, 2006; Vedder et al. 2013, 2014; Smith et al. 2016) and we therefore considered it appropriate to examine sex differences in synaptic plasticity. Responses were
A
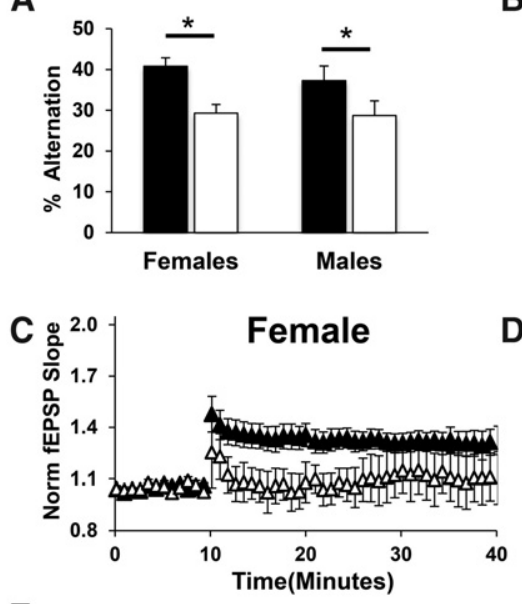

E

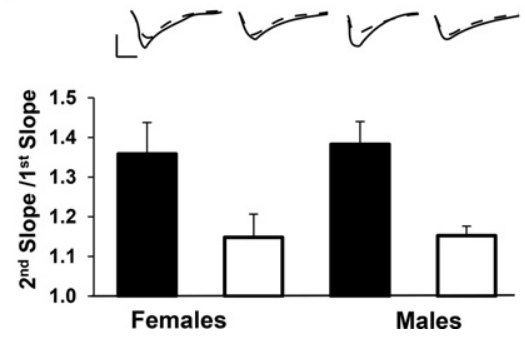

Figure 2. Independent of sex, thiamine deficiency led to impaired spontaneous alternation performance $(A)$, a suppression of hippocampal long-term potentiation (LTP: $B, C, D)$, and a decrease in pairedpulse facilitation (PPF). LTP was induced by high-frequency tetanus $(100 \mathrm{~Hz}, 0.5 \mathrm{sec}, 4 \times, 1.5$ times the baseline voltage) and PPF was recorded during baseline transmission before inducing LTP (50 msec interstimulus interval). 
A

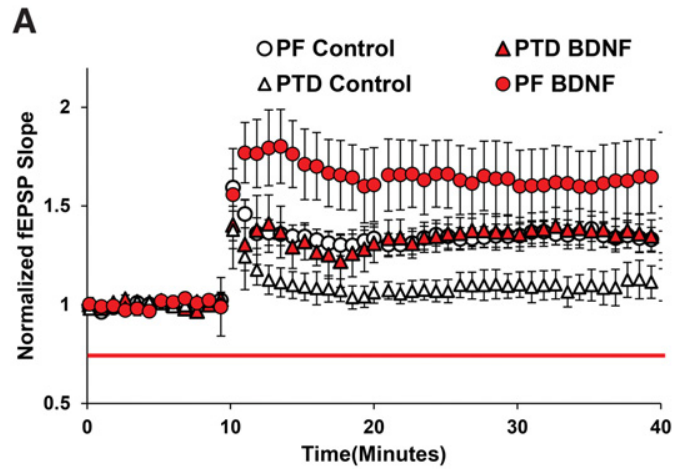

C

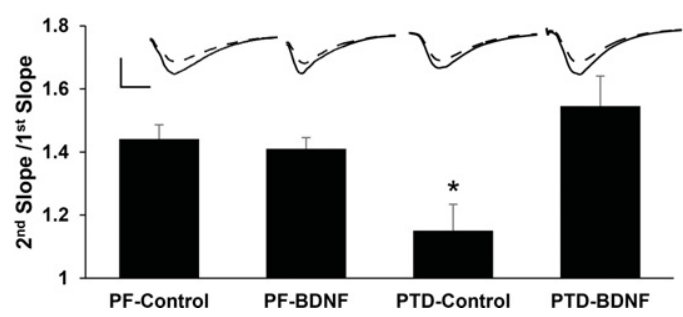

Figure 3. Application of brain-derived neurotrophic factor (BDNF; 20ng/mL) increased LTP in both control (PF) of thiamine-deficient (PTD) rats, returning hippocampal LTP levels in PTD rats to the level of untreated controls $(A, B)$. Furthermore, BDNF normalized paired-pulse facilitation, selectively, in PTD rats $(C)$.

digitized using a DigiData1440A (Molecular Devices) and monitored and stored using pCLAMP 10 software (Molecular Devices). fEPSP slopes were analyzed using Matlab2015b (Mathworks) and data normalized to the pretetanus baseline. Percent LTP was measured as an average of the change from baseline between 10 and 30 min post-tetanus.

LTP was significantly decreased in both male and female rats treated with $\operatorname{PTD}\left(F_{(3,27)}=11.27, P<0.005\right.$, Fig. $\left.2 \mathrm{~B}-\mathrm{D}\right)$. Similar to the behavioral data, the decrease in LTP was not modified by sex $(P>0.17)$. However, the magnitude of LTP in control (PF) male rats was higher than the magnitude of LTP in female PF diestrus (direct comparison using $t$-test, $t_{(17)}=2.11, P<0.05$ ). This increased LTP in male rats compared with female diestrus rats replicates previous findings (Warren et al. 1995). To better understand how TD alters LTP, we analyzed the paired-pulse facilitation (PPF) during baseline transmission before inducing LTP (50 msec interstimulus interval). We found a significant decrease in PPF in rats treated with PTD $\left(F_{(1,27)}=8.72, P<0.01\right)$ and this decrease was not dependent on sex $\left(F_{(1,27)}<1, P>0.88\right.$; see Fig. $\left.2 \mathrm{E}\right)$. The PPF ratio is a physiological measure of the probability of neurotransmitter release from presynaptic terminals (Katz et al. 1993; McCool 2011). An increase in release probability is reflected in a decrease in the PPF ratio. A decrease in PPF in TD rats is somewhat unexpected, considering the decreased magnitude of LTP in these rats. Future studies are needed to elucidate the mechanisms by which TD alters PPF; including using whole-cell recordings to determine whether altered sequential glutamate release is involved. Synapsin 1 presents as a key target as TD reduces the amount of hippocampal phosphorylated synapsin I, which is involved in neurotransmitter release by tethering synaptic vesicles to the actin cytoskeleton (Resende et al. 2012).

The opposite response in the PPF ratio (i.e., larger ratio suggesting reduced glutamate release) has been found in a mouse model of seizure (Zhang et al. 2010). This suggests that the PTD model has a different profile of altered neuroplasticity than commemory performance (Bekinschtein et al. 2011; Chourbaji et al. 2011). Furthermore, both exercise (Hall et al. 2014; Hall and Savage 2016) and environmental enrichment (Wolff et al. 2008; Harland et al. 2014) enhance learning and memory after diencephalic damage. Prolonged exposure to BDNF across days to weeks can reorganize connections between brain regions and increase the survival of injured neurons (Zagrebelsky and Korte 2014). These long-term effects of BDNF on neural survival and structure are complemented by the acute effects of BDNF on synaptic plasticity. Short-term effects of BDNF include almost immediate changes in neurotransmitter release, followed by altered synaptic structure that occurs within minutes, and changes in protein synthesis and gene expression can occur within hours to induce further synaptic changes (Leal et al. 2015).

Specifically, BDNF has been shown to regulate both the induction and maintenance of LTP (Scharfman and MacLusky 2014; Leal et al. 2015). To determine whether BDNF could recover the TD-induced LTP deficit, we bath-applied BDNF $(20 \mathrm{ng} / \mathrm{mL}$, Peprotech) during baseline recording before delivering HFS to induce LTP. We found that BDNF significantly increases the LTP magnitude (Fig. 3A-B, $F_{(1,53)}=4.79, P<0.05$ ) and this increase was not dependent on sex (BDNF $\times$ Sex Interaction, $F_{(1,53)}<1$, $P>0.82$, data not shown). Analysis of baseline PPF unveiled a significant interaction between BDNF application and TD treatment (Fig. 3C, $\left.F_{(1,53)}=11.192, P<0.005\right)$. Although an alteration in PPF is suggestive of presynaptic dysfunction (Katz et al. 1993; McCool 2011), the procedures followed in this experiment are not a direct test of that mechanism. However, in hippocampal cultures an acute exogenous application of BDNF has been shown to enhance presynaptic efficacy by increasing glutamate release at a significant number of excitatory synapses (Lessmann et al. 1994; Lessmann and Heumann 1998). Furthermore, a chronic application of BDNF enhances the docking of transmitter vesicles also, leading to an increase in release of glutamate, and this process appears to involve TrkB-dependent phosphorylation of synapsin I 
(Tyler and Pozzo-Miller 2001; Tyler et al. 2002). However, it is unknown whether TD-induced BDNF dysfunction occurs at the level of hippocampal synapses or whether altered BDNF levels after TD are causal to the impairment of either LTP, PPF, or spatial memory. Our data do suggest that BDNF is sufficient to recover these synaptic deficits.

In summary, these experiments are the first to use electrophysiology to investigate the effects of TD on hippocampal synaptic function. We show that a long-lasting deficit in LTP occurs after exposure to moderate-to-severe TD, and this effect is independent of sex. However, this does not rule out that sex difference may exist in other models of alcohol-related brain damage. Compared with studies that assessed the effects of chronic ethanol alone (Durand and Carlen 1984; Tremwel and Hunter 1994), we can conclude that TD leads to a more persistent and a greater deficit in hippocampal synaptic function. We further show that TD decreased PPF, suggesting that diencephalic damage may lead to dysfunction in presynaptic transmission within the hippocampus. An exogenous application of BDNF recovered hippocampal synaptic function following TD, as the decreased magnitude of both LTP and PPF were restored. These data provide further evidence that BDNF is important to modulate plasticity and neural adaptation within the hippocampal-diencephalic circuit (Tsanov et al. 2011). Thus, manipulations that increase BDNF levels, such as environmental enrichment and exercise, are an avenue to improve hippocampal plasticity that is downgraded after diencephalic damage.

\section{Acknowledgments}

This research was funded by grants from the NIAAA (RO1AA021775; R01AA021775-03S1) and the NINDS (R21NS085502) to L.M.S. In addition, the authors thank Timothy Hillis, Sierra Wallace, and Joshua Glynn for their assistance with the preparations for these experiments.

\section{References}

Aggleton JP, Nelson AJD. 2015. Why do lesions in the rodent anterior thalamic nuclei cause such severe spatial deficits? Neurosci Biobehav Rev 54: $131-144$.

Aggleton JP, Neave N, Nagle S, Hunt PR. 1995. A comparison of the effects of anterior thalamic, mamillary body and fornix lesions on reinforced spatial alternation. Behav Brain Res 68: 91-101.

Armstrong-James M, Ross DT, Chen F, Ebner FF. 1988. The effect of thiamine deficiency on the structure and physiology of the rat forebrain. Metab Brain Dis 3: 91-124.

Bekinschtein P, Oomen CA, Saksida LM, Bussey TJ. 2011. Effects of environmental enrichment and voluntary exercise on neurogenesis, learning and memory, and pattern separation: BDNF as a critical variable? Semin Cell Dev Biol 22: 536-542.

Chourbaji S, Brandwein C, Gass P. 2011. Altering BDNF expression by genetics and/or environment: impact for emotional and depression-like behaviour in laboratory mice. Neurosci Biobehav Rev 35: 599-611.

Dumont JR, Amin E, Poirier GL, Albasser MM, Aggleton JP. 2012. Anterior thalamic nuclei lesions in rats disrupt markers of neural plasticity in distal limbic brain regions. Neuroscience 224-248: 81-101.

Dupire A, Kant P, Mons N, Marchand AR, Coutureau E, Dalrymple-Alford J, Wolff M. 2013. A role for anterior thalamic nuclei in affective cognition: interaction with environmental conditions. Hippocampus 23: $392-404$.

Durand D, Carlen PL. 1984. Impairment of long-term potentiation in rat hippocampus following chronic ethanol treatment. Brain Res 308: 325-332.

Hall JM, Savage LM. 2016. Exercise leads to the re-emergence of the cholinergic/nestin neuronal phenotype within the medial septum/ diagonal band and subsequent rescue of both hippocampal ACh efflux and spatial behavior. Exp Neurol 278: 62-75.

Hall JM, Vetreno RP, Savage LM. 2014. Differential cortical neurotrophin and cytogenetic adaptation after voluntary exercise in normal and amnestic rats. Neuroscience 258: 131-146.
Harland BC, Collings DA, McNaughton N, Abraham WC, Dalrymple-Alford JC. 2014. Anterior thalamic lesions reduce spine density in both hippocampal CA1 and retrosplenial cortex, but enrichment rescues CA1 spines only. Hippocampus 24: 1232-1247.

Harper C. 1983. The incidence of Wernicke's encephalopathy in Australia-a neuropathological study of 131 cases. I Neurol Neurosurg Psychiatry 46: 593-598.

Katz PS, Kirk MD, Govind CK. 1993. Facilitation and depression at different branches of the same motor axon: evidence for presynaptic differences in release. J Neurosci 13: 3075-3089.

Kauer JA, Malenka RC, Nicoll RA. 1988. NMDA application potentiates synaptic transmission in the hippocampus. Nature 334: 250-252.

Kopelman MD, Thomson AD, Guerrini I, Marshall EJ. 2009. The Korsakoff syndrome: clinical aspects, psychology and treatment. Alcohol Alcohol 44: $148-154$.

Langlais PJ, Zhang SX, Savage LM. 1996. Neuropathology of thiamine deficiency: an update on the comparative analysis of human disorders and experimental models. Metab Brain Dis 11: 19-37.

Leal G, Afonso PM, Salazar IL, Duarte CB. 2015. Regulation of hippocampal synaptic plasticity by BDNF. Brain Res 1621: $82-101$.

Lennartz RC. 2008. The role of extramaze cues in spontaneous alternation in a plus-maze. Learn Behav 36: 138-144.

Lessmann V, Heumann R. 1998. Modulation of unitary glutamatergic synapses by neurotrophin-4/5 or brain-derived neurotrophic factor in hippocampal microcultures: presynaptic enhancement depends on pre-established paired-pulse facilitation. Neuroscience 86: 399-413.

Lessmann V, Gottmann K, Heumann R. 1994. BDNF and NT-4/5 enhance glutamatergic synaptic transmission in cultured hippocampal neurones. Neuroreport 6: $21-25$.

Mair RG. 1994. On the role of thalamic pathology in diencephalic amnesia. Rev Neurosci 5: 105-140.

Malenka RC, Bear MF. 2004. LTP and LTD: an embarrassment of riches. Neuron 44: 5-21.

Mancinelli R, Barlocci E, Ciprotti M, Senofonte O, Fidente RM, Draisci R, Attilia ML, Vitali M, Fiore M, Ceccanti M. 2013. Blood thiamine, zinc, selenium, lead and oxidative stress in a population of male and female alcoholics: clinical evidence and gender differences. Ann Ist Super Sanita 49: $65-72$.

McCarthy MM, Arnold AP, Ball GF, Blaustein JD, De Vries GJ. 2012. Sex differences in the brain: the not so inconvenient truth. J Neurosci 32: 2241-2247.

McCool BA. 2011. Ethanol modulation of synaptic plasticity. Neuropharmacology 61: 1097-1108.

Mohler EG, Baker PM, Gannon KS, Jones SS, Shacham S, Sweeney JA, Ragozzino ME. 2012. The effects of PRX-07034, a novel 5-HT6 antagonist, on cognitive flexibility and working memory in rats. Psychopharmacology 220: 687-696.

Nixon SJ, Prather R, Lewis B. 2014. Sex differences in alcohol-related neurobehavioral consequences. Handb Clin Neurol 125: 253-272.

Peris J, Anderson KJ, Vickroy TW, King MA, Hunter BE, Walker DW. 1997. Neurochemical basis of disruption of hippocampal long term potentiation by chronic alcohol exposure. Front Biosci 2: d309-d316.

Pitel AL, Zahr NM, Jackson K, Sassoon SA, Rosenbloom MJ, Pfefferbaum A, Sullivan EV. 2011. Signs of preclinical Wernicke's encephalopathy and thiamine levels as predictors of neuropsychological deficits in alcoholism without Korsakoff's syndrome. Neuropsychopharmacology 36: $580-588$.

Pitkin SR, Savage LM. 2004. Age-related vulnerability to diencephalic amnesia produced by thiamine deficiency: the role of time of insult. Behav Brain Res 148: 93-105.

Ragozzino ME, Artis S, Singh A, Twose TM, Beck JE, Messer WS Jr. 2012. The selective M1 muscarinic cholinergic agonist CDD-0102A enhances working memory and cognitive flexibility. J Pharmacol Exp Ther 340: 588-594.

Reid IC, Stewart CA. 1997. Seizures, memory and synaptic plasticity. Seizure 6: $351-359$.

Resende LS, Ribeiro AM, Werner D, Hall JM, Savage LM. 2012. Thiamine deficiency degrades the link between spatial behavior and hippocampal synapsin I and phosphorylated synapsin I protein levels. Behav Brain Res 232: 421-425.

Savage LM, Chang Q, Gold PE. 2003. Diencephalic damage decreases hippocampal acetylcholine release during spontaneous alternation testing. Learn Mem 10: 242-246.

Savage LM, Hall JM, Resende LS. 2012. Translational rodent models of Korsakoff syndrome reveal the critical neuroanatomical substrates of memory dysfunction and recovery. Neuropsychol Rev 22: 195-209.

Scharfman HE, MacLusky NJ. 2014. Differential regulation of BDNF, synaptic plasticity and sprouting in the hippocampal mossy fiber pathway of male and female rats. Neuropharmacology 76(Pt C): 696-708.

Scoville WB, Milner B. 1957. Loss of recent memory after bilateral hippocampal lesions. J Neurochem 20: 11-21. 
Smith CC, McMahon LL. 2005. Estrogen-induced increase in the magnitude of long-term potentiation occurs only when the ratio of NMDA transmission to AMPA transmission is increased. J Neurosci 25: 7780-7791.

Smith CC, McMahon LL. 2006. Estradiol-induced increase in the magnitude of long-term potentiation is prevented by blocking NR2B-containing receptors. J Neurosci 26: 8517-8522.

Smith CC, Smith LA, Bredemann TM, McMahon LL. 2016. $17 \beta$ estradiol recruits GluN2B-containing NMDARs and ERK during induction of long-term potentiation at temporoammonic-CA1 synapses. Hippocampus. 26: 110-117.

Stewart C, Jeffery K, Reid I. 1994. LTP-like synaptic efficacy changes following electroconvulsive stimulation. Neuroreport 5: 1041-1044.

Tremwel MF, Hunter BE. 1994. Effects of chronic ethanol ingestion on long-term potentiation remain even after a prolonged recovery from ethanol exposure. Synapse 17: 141-148.

Tsanov M, Vann SD, Erichsen JT, Wright N, Aggleton JP, O’Mara SM. 2011. Differential regulation of synaptic plasticity of the hippocampal and the hypothalamic inputs to the anterior thalamus. Hippocampus 21: 1-8.

Tulving E. 1987. Multiple memory systems and consciousness. Hum Neurobiol 6: 67-80.

Tyler WJ, Pozzo-Miller LD. 2001. BDNF enhances quantal neurotransmitter release and increases the number of docked vesicles at the active zones of hippocampal excitatory synapses. J Neurosci 21: 4249-4258.

Tyler WJ, Alonso M, Bramham CR, Pozzo-Miller LD. 2002. From acquisition to consolidation: on the role of brain-derived neurotrophic factor signaling in hippocampal-dependent learning. Learn Mem 9: 224-237.

Vedder LC, Smith CC, Flannigan AE, McMahon LL. 2013.

Estradiol-induced increase in novel object recognition requires hippocampal NR2B-containing NMDA receptors. Hippocampus 23: $108-115$.
Vedder LC, Bredemann TM, McMahon LL. 2014. Estradiol replacement extends the window of opportunity for hippocampal function. Neurobiol Aging 35: 2183-2192.

Vedder LC, Hall JM, Jabrouin KR, Savage LM. 2015. Interactions between chronic ethanol consumption and thiamine deficiency on neural plasticity, spatial memory, and cognitive flexibility. Alcohol Clin Exp Res 39: $2143-2153$.

Warren SG, Humphreys AG, Juraska JM, Greenough WT. 1995. LTP varies across the estrous cycle: enhanced synaptic plasticity in proestrus rats. Brain Res 703: 26-30.

Wolff M, Loukavenko EA, Will BE, Dalrymple-Alford JC. 2008. The extended hippocampal-diencephalic memory system: enriched housing promotes recovery of the flexible use of spatial representations after anterior thalamic lesions. Hippocampus 18: 996-1007.

Zagrebelsky M, Korte M. 2014. Form follows function: BDNF and its involvement in sculpting the function and structure of synapses. Neuropharmacology 76(Pt C): 628-638.

Zhang SX, Weilersbacher GS, Henderson SW, Corso T, Olney JW, Langlais PJ. 1995. Excitotoxic cytopathology, progression, and reversibility of thiamine deficiency-induced diencephalic lesions. J Neuropathol Exp Neurol 54: 255-267.

Zhang Y, Cai GE, Yang Q, Lu QC, Li ST, Ju G. 2010. Time-dependent changes in learning ability and induction of long-term potentiation in the lithium-pilocarpine-induced epileptic mouse model. Epilepsy Behav 17: $448-454$.

Received August 28, 2016; accepted in revised form November 2, 2016. 


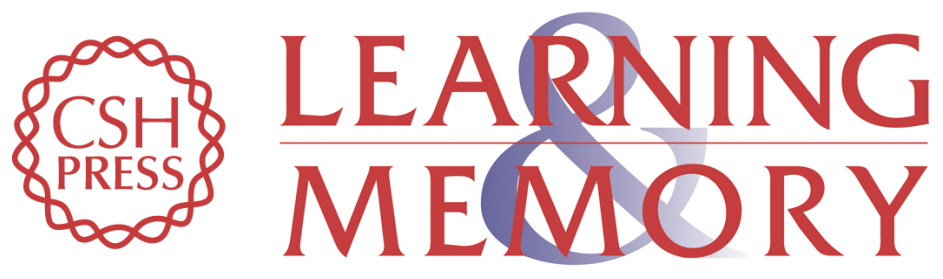

\section{BDNF regains function in hippocampal long-term potentiation deficits caused by diencephalic damage}

Lindsey C. Vedder and Lisa M. Savage

Learn. Mem. 2017, 24:

Access the most recent version at doi:10.1101/Im.043927.116

References This article cites 54 articles, 9 of which can be accessed free at: http://learnmem.cshlp.org/content/24/2/81.full.html\#ref-list-1

Creative This article is distributed exclusively by Cold Spring Harbor Laboratory Press for the Commons License first 12 months after the full-issue publication date (see

http://learnmem.cshlp.org/site/misc/terms.xhtml). After 12 months, it is available under a Creative Commons License (Attribution-NonCommercial 4.0 International), as described at http://creativecommons.org/licenses/by-nc/4.0/.

Email Alerting Receive free email alerts when new articles cite this article - sign up in the box at the Service top right corner of the article or click here. 